\title{
CeSaM, as células do sangue menstrual: Gênero, tecnociência e terapia celular
}

\author{
Daniela Tonelli Manica* \\ Regina Coeli dos Santos Goldenberg** \\ Karina Dutra Asensi***
}

\begin{abstract}
Resumo
Neste experimento de coautoria multidisciplinar, desenvolvemos a proposta de seguir, etnograficamente, as CeSaM - "células do sangue menstrual". Trata-se de pensar diferentes agenciamentos de fluidos e substâncias corporais, como o sangue menstrual, no universo da tecnociência brasileira. 0 artigo apresenta alguns dos resultados de uma pesquisa de cunho socioantropológico sobre as atividades que envolvem o uso de sangue menstrual para obtenção de células estromais mesenquimais, desenvolvidas pelo Laboratório de Cardiologia Celular e Molecular (LCCM) do Instituto de Biofísica Carlos Chagas Filho (IBCCF), da Universidade Federal do Rio de Janeiro (UFRJ). Procuramos contextualizar o desenvolvimento dessas pesquisas, demonstrar o processo de ontogênese das CeSaM e discutir algumas das dimensões de gênero que podem ser pensadas a partir do engajamento do sangue menstrual, e suas células, nas pesquisas científicas sobre células-tronco.
\end{abstract}

\section{Palavras-chave}

Antropologia da ciência e da tecnologia. Gênero. Células mesenquimais. Sangue menstrual.

\section{Abstract}

In this experiment of multidisciplinary co-authorship we develop the idea of following, ethnographically, the CeSaM - menstrual blood cells. We intend to think different agencies

\footnotetext{
* Daniela Tonelli Manica é doutora em Antropologia Social pela Universidade Estadual de Campinas (Unicamp), desde 2009; e pesquisadora do Laboratório de Estudos Avançados em Jornalismo Científico (Labjor) da Unicamp. Email: dtmanica@unicamp.br .

** Regina Coeli dos Santos Goldenberg é doutora em Ciências Biológicas - Biofísica pela Universidade Federal do Rio Janeiro (UFRJ), desde 1995; e professora Associada do Instituto de Biofísica Carlos Chagas Filho e dos Programas de Pós-Graduação em Ciências Biológicas (Fisiologia) e Medicina (Radiologia) / UFRJ. Email: rcoeli@biof.ufrj.br .

***Karina Dutra Asensi é Doutora em Ciências Biológicas - Fisiologia pela Universidade Federal do Rio de Janeiro (UFRJ), desde 2016; pós-doutoranda do Instituto de Biofísica Carlos Chagas Filho / UFRJ; e professora substituta do Centro Nacional de Biologia Estrutural e Bioimagem / UFRJ. Email: karina_asensi@yahoo.com.br .
} 
of substances and body fluids, such as the menstrual blood, in the universe of Brazilian technoscience. The article presents some of the results of a socio-anthropological research about the activities that involve the use of menstrual blood to obtain mesenchymal stromal cells, developed by the Laboratory of Cell and Molecular Cardiology (LCCM) at the Carlos Chagas Filho Biophysics Institute (IBCCF), Federal University of Rio de Janeiro (UFRJ), Brazil. We contextualize the development of these researches, demonstrate the process of ontogenesis of CeSaM and discuss some of the gender dimensions that may be thought from the engagement of menstrual blood, and its cells, on scientific research about stem cells.

\section{Keywords}

Anthropology of science and technology. Gender. Mesenchymal stromal cells. Menstrual blood.

\section{Introdução}

Este texto resulta de uma pesquisa que tem como objetivo geral pensar diferentes agenciamentos de fluidos e substâncias corporais, como o sangue menstrual. Apresentamos alguns dos resultados de uma pesquisa de cunho socioantropológico sobre as atividades que envolvem o uso de sangue menstrual para obtenção de células estromais mesenquimais, desenvolvidas pelo Laboratório de Cardiologia Celular e Molecular (LCCM) do Instituto de Biofísica Carlos Chagas Filho (IBCCF), da Universidade Federal do Rio de Janeiro (UFRJ).

O material apresentado foi elaborado a partir da pesquisa etnográfica feita pela primeira autora (professora e pesquisadora com formação na área da Antropologia) no laboratório em questão, no qual há muitos anos atuam as duas demais autoras, a primeira, como professora associada e a segunda, atualmente como pós-doutoranda, mas tendo realizado suas pesquisas de mestrado e doutorado no referido laboratório, especificamente com as células derivadas do sangue menstrual (ambas com formação na área das Ciências Biológicas).

Este texto é um experimento de coautoria multidisciplinar, no qual nos propusemos a escrever coletivamente o artigo, partindo da pesquisa etnográfica da primeira autora no laboratório. Esta pesquisa vem sendo desenvolvida desde 2015 e compreende o acompanhamento presencial de alguns dos experimentos laboratoriais realizados com o sangue menstrual, 
seu registro fotográfico, entrevistas com as pesquisadoras sobre esses procedimentos e seus resultados, bem como diversas conversas e trocas a respeito das temáticas em questão: corpo; gênero; tecnociência e saúde; terapia celular, medicina regenerativa e bioengenharia.

Desenvolvemos aqui a proposta de seguir, etnograficamente, as CeSaM, "células do sangue menstrual". Procuramos, para isso, contextualizar o desenvolvimento dessas pesquisas no laboratório, demonstrar o processo de ontogênese das CeSaM e discutir algumas das dimensões de gênero que podem ser pensadas a partir do engajamento do sangue menstrual, e suas células, nas pesquisas científicas sobre células-tronco.

\section{Corpo e Gênero}

Ao analisar o discurso médico estadunidense da segunda metade do século XX sobre o corpo da mulher, Emily Martin (2006) demonstra o quanto a sua fisiologia é interpretada de acordo com o paradigma reprodutivo. Assim, a menstruação é caracterizada como uma "falha" no processo de reprodução, e vista como uma experiência eminentemente negativa e de perda (de sangue, do ciclo fértil, de um possível feto). Da mesma forma, a menopausa é interpretada como o ocaso da vida (reprodutiva). Ambos fenômenos (menstruação e menopausa) se constituem, no argumento da autora, a partir de uma metáfora industrial na qual o corpo feminino é visto como sendo uma "fábrica" voltada para a produção de bebês (MARTIN, 2006).

A hipótese inicial, que motivou a pesquisa etnográfica e o encontro entre as autoras, incluía uma indagação sobre a possível rentabilidade, numa perspectiva feminista contrária à visão médica delineada por Martin (2006), de se falar sobre a positividade (inclusive científica) do sangue menstrual. Ou de pensar a possibilidade de tornar o sangue menstrual algo capaz de "fazer alguma coisa" (LATOUR; STARK, 1999): no caso, células que servem para fazer ciência e, eventualmente, servirão para tratamentos de saúde.

Apesar das ressalvas e críticas a uma abordagem essencialista do corpo e do gênero, e da importância de um olhar interseccional sobre qualquer temática dessa natureza, superar concepções como a de que a menstruação é uma "sangria inútil", uma fonte de patologias, que deve ser suprimida (COUTINHO, 1996), ou mesmo a possibilidade de repensar a abjeção que marca a relação das mulheres com seu próprio corpo e fluidos corporais, e ressignificar positivamente seus fluidos e órgãos (MANICA; RIOS, 2017), 
parece ser algo que caminha no sentido de uma maior valorização do corpo entendido (e marcado como) feminino no mundo. Ou, ainda, de libertação de uma visão teleológica e androcêntrica da fisiologia "reprodutiva" dos corpos que têm útero.

Experiências corporificadas e viscerais vêm (re)tomando um lugar mais central nas questões relacionadas a corpo, gênero e reprodução. Parte dos estudos sociais da ciência e tecnologia tem tentado dar conta dessa questão reexercitando um diálogo produtivo entre as ciências sociais e a biologia/biomedicina e tentando superar a tendência crítica baseada no construcionismo social, que minimiza a importância do corpo na definição do gênero (WILSON, 2015; BUTLER, 1993; HARAWAY, 1990).

No Brasil, podemos situar trabalhos na interface entre as ciências sociais (antropologia, sociologia, saúde coletiva) e os movimentos feministas, que trazem a temática da reprodução e do corpo feminino, seja através da discussão sobre parto humanizado e parto natural (FLEISCHER, 2011; TORNQUIST, 2002; CARNEIRO, 2014), seja das denúncias de violência obstétrica e a "epidemia" de cesarianas no Brasil (DINIZ, 2005); ou ainda das discussões sobre aleitamento materno e o mercado de leite em pó industrializado (ALZUGUIR; NUCCI, 2015; ALMEIDA, 1999)1․

Diversas críticas (não só no âmbito do "gênero") à (bio)medicalização dos corpos situam o problema na expansão da indústria farmacêutica, vista como a principal aliada da tecnociência médica na resolução das mais diversas aflições pela via do consumo de medicamentos. Nesse contexto, uma "resistência" possível à biopolítica contemporânea se ancoraria na recusa às intervenções e autoridades médicas. Consequentemente, intensifica-se uma (re)valorização de experiências viscerais como o parto vaginal e caseiro, a amamentação e também a menstruação (DINIZ, 2005; CARNEIRO, 2014; ALZUGUIR; NUCCI, 2015; BOBEL, 2010; BOBEL; KISSLING, 2011). Experiências que competem com as diversas técnicas já estabilizadas pela biomedicina high tech.

Assim, ao mesmo tempo que mulheres de classe média/alta urbana, nas grandes cidades brasileiras, se "chipam" com implantes hormonais para ficar períodos prolongados sem menstruar, sem ovular, com mais libido,

\footnotetext{
${ }^{1}$ Estamos conscientes de que esses exemplos compõem um recorte limitado, marcado por afinidades e afetos, e que deixa de fora muitos outros trabalhos, bem como as articulações com raça e sexualidade.
} 
mais musculosas e sem celulite (MANICA; NUCCI, 2017), outras passaram a coletar e reutilizar, através de técnicas corporais diversas, suas placentas, leite materno, cordão umbilical e sangue menstrual ${ }^{2}$. Ou seja, a colocar esses tecidos e substâncias em novos fluxos que os previamente dados (CARSTEN, 2013), ou constituídos como "seguros" ao longo do processo de medicalização e expansão da biomedicina na área reprodutiva.

No caso da placenta e do sangue menstrual, contudo, são tecidos cujas materialidades passaram a se tornar mais palpáveis, visíveis e valorizadas nos últimos anos, a partir do compartilhamento de técnicas corporais que envolvem uma reapropriação de experiências fisiológicas e da capacidade de agência sobre elas (CARNEIRO, 2012; MANICA; RIOS, 2017). O que parece estar em jogo é a possibilidade de manejo desses tecidos, a reivindicação do direito de definir seu destino e de, possivelmente, produzir novos agenciamentos ${ }^{3}$.

Partindo então do pressuposto de que há uma convergência entre os agenciamentos possíveis de partes do corpo e uma agenda política que afeta as percepções e valores relacionados a gênero, apresentamos a seguir algumas reflexões acerca das pesquisas científicas sobre a presença de células-tronco no sangue menstrual.

\footnotetext{
${ }^{2}$ Podemos considerar que para o leite materno práticas de circulação dessa substância tenham sido mais presentes na história das relações sociais, e raciais, no Brasil - não só com os bancos de leite mas também, por exemplo, até alguns séculos atrás, com as figuras das amas-de-leite, em geral mulheres negras escravizadas que amamentavam os bebês das mulheres brancas. Os bancos de leite materno procuram atualmente, no Brasil, organizar esse fluxo de substâncias através da ética da doação anônima e voluntária. Numa perspectiva transespecífica, podemos localizar também as vacas como provedoras desse alimento para grande parte da população humana, em geral em contextos de comercialização do leite em diversos formatos e embalagens, e com diferentes graus de processamento (FINE, 2003; FLEISCHER, 2007). Sobre a comercialização de tecidos e substratos corporais em outros contextos nacionais, ver Waldby e Mitchell (2006).

${ }^{3}$ Diversas performances artísticas, exposições, fotografias colocam o sangue menstrual em evidência, como objeto artístico (BOBEL, 2010; BERTHON-MOINE, 2011; BOBEL; KISSLING, 2011). Eles servem também como formas materiais de se produzir registros com finalidade de recordação pessoal sobre a experiência do parto (no caso do registro imagético da placenta e do cordão umbilical). Essas imagens, bem como outras menos circunscritas aos universos estabilizados da arte, mais "caseiras" e "pessoais", têm sido amplamente replicadas em divulgações nas diversas redes sociais digitais, explorando a potência estética e política do "vermelho" do sangue menstrual, ou do desenho impresso pela placenta após o parto em um suporte (tecido, papel). Ou ainda, sua presença feita visível pelo registro fotográfico do parto como evento a ser lembrado.
} 
Buscamos apresentar as dificuldades de tornar presente e ativa, no laboratório, uma substância tão marcada por gênero - o sangue menstrual - e explorar, a partir dos resultados obtidos nas pesquisas já realizadas, a ideia de que ele seria um substrato corporal eficaz para pesquisa científica e o desenvolvimento das células estromais mesenquimais ${ }^{4}$.

\section{Pesquisas com Células-Tronco no LCCM / IBCCF / UFRJ}

O tema da utilização de embriões humanos em pesquisas científicas já foi amplamente discutido no momento em que as células-tronco se tornaram uma via promissora de pesquisas e tratamentos (LUNA, 2007; CESARINO, 2007; PEREIRA, 2008; MEDEIROS, 2012; NOBRE; PEDRO, 2014). As célulastronco embrionárias, para além de toda a rentabilidade na discussão sobre o que é, e quando começa, a vida; o que é o indivíduo ou a pessoa; o que é/pode ser o humano; têm também um potencial específico, e muito mais expressivo, para o conhecimento sobre os processos biológicos envolvidos na diferenciação celular, que poderiam levar a tratamentos eficazes nas áreas de medicina regenerativa, terapia celular e bioengenharia (LUNA, 2007).

(Im)possibilidades científicas (como a alta taxa de proliferação dessas células, que pode causar tumores) e entraves bioéticos para utilizar esse tipo de material de pesquisa promoveram a busca por outros tecidos corporais que também tivessem células-tronco, ainda que não as embrionárias. As mais conhecidas e utilizadas são as células derivadas da medula óssea. Neste caso, trata-se de células-tronco adultas que não são totipotentes (como as do zigoto) nem pluripotentes (como as embrionárias), mas "multipotentes", isto é, são células com "uma capacidade de diferenciação limitada", que se diferenciam "em linhagens relacionadas com seus tecidos de origem" (CARVALHO; GOLDENBERG; BRUNSWICK, 2012, p.3). ${ }^{5}$

\footnotetext{
${ }^{4}$ Células "estromais" são derivadas do tecido de sustentação de um órgão, capazes de fornecer suporte a outros tipos celulares.

${ }^{5}$ As células "totipotentes" são capazes de dar origem a qualquer tipo celular do organismo, formando todos os tecidos que compõem o embrião, bem como os anexos embrionários (por exemplo, a placenta) necessários para o seu desenvolvimento. As "pluripotentes" são capazes de se diferenciar em qualquer tipo celular também, entretanto, não possuem a capacidade de desenvolver um indivíduo adulto, já que não são capazes de dar origem aos anexos embrionários. Já as células "multipotentes" possuem capacidade de diferenciação mais limitada, dando origem somente a células relacionadas ao seu tecido de origem.
} 
Há duas vantagens dessas células em relação às embrionárias/ pluripotentes: por terem uma menor capacidade de proliferação, seu uso diminui as chances de formação de tumores nos pacientes submetidos às terapias celulares. É possível também a utilização da própria célula do paciente no tratamento, o que reduz o risco de rejeição imunológica, configurando o que se costuma chamar de um tratamento "autólogo" (nos quais se utilizam as células do próprio paciente) (CARVALHO; GOLDENBERG; BRUNSWICK, 2012, p.4; LUNA, 2007).

Além da medula óssea, as células-tronco mesenquimais ${ }^{6}$ podem ser extraídas de diversos outros "nichos" do organismo (PEREIRA, 2008, p.10), como: cordão umbilical, tecido adiposo, placenta, coração, líquido amniótico, polpa do dente de leite e, finalmente, o sangue menstrual. Atualmente, a comunidade científica concorda que o potencial terapêutico das células mesenquimais não está relacionado à sua capacidade de diferenciação em outros tipos celulares, e sim à liberação de fatores e substâncias benéficas (o que é conhecido como "efeito parácrino"). Portanto, a terminologia mais adequada para nomear essa população celular é célula estromal mesenquimal.

As pesquisas com sangue menstrual se inserem principalmente nas linhas de pesquisa do laboratório ${ }^{7}$ que investigam o cultivo de células estromais mesenquimais e terapias celulares para doenças cardíacas e hepáticas. Envolvem, portanto, uma compreensão das funções e potências das células presentes na camada mais interna do útero, o endométrio, que descama durante a menstruação. Trabalham também as possibilidades de explorar o uso dessas células, em terapia celular, para tratar disfunções como o infarto do miocárdio.

As pesquisas exploram possibilidades de terapia celular, por exemplo, na bioengenharia, que envolve o uso de células-tronco desenvolvidas em laboratório para o transplante de órgãos (que são "descelularizados" 8 e "repopulados" com células do próprio paciente/receptor). Esse

\footnotetext{
${ }^{6}$ As células mesenquimais têm características multipotentes, presentes em diversos tecidos e órgãos.

7 Criado em 1985, o Laboratório de Cardiologia Celular e Molecular do IBCCF/UFRJ desenvolve pesquisas que se subdividem em diversas linhas. Disponível em: http://www. biof.ufrj.br/pt-br/lab-tot/49\%20.

${ }^{8} \mathrm{O}$ processo de descelularização envolve a remoção de todas as células de um órgão através do uso de agentes químicos.
} 
procedimento reduziria o risco de rejeição imunológica nos órgãos doados. Há, ainda, pesquisas sobre os efeitos dessas células após o procedimento de injeção das mesmas em órgãos lesados (como o coração, em um evento de infarto do miocárdio, por exemplo). Investigam-se nesse caso, efeitos como o "parácrino", que compreende determinadas sinalizações celulares e moleculares (como a secreção de substâncias específicas), que poderiam agir positivamente na restauração de órgãos, tecidos, células danificadas.

Um dos objetivos principais, portanto, é a produção de células-tronco em laboratório que possam ser utilizadas em terapias celulares sobre a doença (hepática ou cardíaca), de modo a revertê-la ou atenuá-la. Para isso, as pesquisas compreendem um processo de "isolamento, cultivo e expansão" de células provenientes de diversos tecidos corporais humanos adultos.

\section{As CeSaM: Células Derivadas do Sangue Menstrual}

Apesar de a existência de células-tronco no endométrio, tecido que reveste internamente o útero, ter sido pressuposta desde a década de 1970, foi somente a partir de 2004 que pesquisadores conseguiram demonstrar esse potencial através de tecidos de pacientes histerectomizadas (que tiveram o útero retirado). Uma forma de obter essas células a partir de procedimentos menos invasivos (como a coleta do sangue menstrual) somente se provou possível em 2007 (ASENSI; GOLDENBERG; PAREDES, 2012, p. 112).

A primeira pesquisa utilizando sangue menstrual para fins terapêuticos foi feita para tratar a distrofia muscular (CUI et al., 2007). As células do sangue menstrual mostraram-se capazes de se diferenciar em células musculares (miócitos) e auxiliar a reparação das células atrofiadas pela doença. Entre as conclusões do artigo, os autores destacam que as "células derivadas do sangue menstrual humano são obtidas por um procedimento simples, seguro e que não causa dor, e podem ser expandidas eficientemente in vitro", ao contrário dos procedimentos invasivos para obter células de fontes como a medula óssea e o tecido adiposo, que envolvem uma operação ou um procedimento doloroso e complicado. Além disso, enfatizam que essas células derivadas do sangue menstrual possuem "uma alta capacidade de autorrenovação", ao contrário dos mioblastos ${ }^{9}$, que vinham sendo usado

\footnotetext{
${ }^{9}$ Mioblastos são células musculares mais imaturas, pouco diferenciadas.
} 
nos procedimentos de pesquisa na área, e que envelheciam rapidamente e expandiam muito pouco (CUI et al., 2007, p. 1593, tradução livre).

Os resultados, promissores, transformaram então o sangue menstrual numa "fonte muito atraente de investigação" (ASENSI; GOLDENBERG; PAREDES, 2012, p. 112). No LCCM, a professora e pesquisadora Regina Goldenberg tomou a iniciativa de experimentar o desenvolvimento dessa cultura de células, apesar de uma resistência inicial mais difusa ao uso do sangue menstrual em laboratório, comparado aos demais tecidos mais usualmente pesquisados (como a medula óssea ou o cordão umbilical).

Apesar de marginais em relação às outras culturas de células, as CeSaM acabaram sendo usadas numa das primeiras pesquisas sobre a reprogramação de células adultas em células de pluripotência induzida no Brasil. Ou seja, uma célula adulta é "convencida" por meio de adição de substâncias a voltar ao estágio de célula embrionária - procedimento descrito pela primeira vez por Shinya Yamanaka e colaboradores em 2006 (TAKAHASHI; YAMANAKA, 2006) e atualmentejá estabilizado, mas quena ocasião estava começando a ser testado. Na ausência de doadores de células humanas adultas de outra procedência, e considerando que Goldenberg e Asensi já mantinham uma quantidade razoável de CeSaM desenvolvidas no laboratório, elas foram, então, engajadas nesse experimento de reprogramação que fazia parte da pesquisa de pós-doutorado de Deivid Rodrigues.

As pesquisas geraram células pluripotentes induzidas (iPS) ${ }^{10}$ a partir das células estromais mesenquimais derivadas do sangue menstrual. Os pesquisadores notaram que as células iPS foram reprogramadas num período curto (de 15 a 17 dias), com uma alta eficiência (2-5\%) se comparada com os fibroblastos $(0,01-0,1 \%)$, que vinham até então sendo usados para essa finalidade. Concluíram, com isso, similarmente ao artigo de Cui, que a CeSaM é uma célula bastante atrativa, uma vez que se reprograma mais rapidamente e mais eficientemente. A pesquisa resultou em um artigo, publicado na revista Cell Transplantation, no qual os autores ressaltam os benefícios de utilização dessa célula, que pode ser "facilmente obtida de um material que é descartável, com procedimentos não invasivos" (Rodrigues

\footnotetext{
${ }_{10}$ As células pluripotentes induzidas são derivadas de células adultas, que já estavam plenamente diferenciadas, mas que foram induzidas em laboratório a voltar para seu estágio embrionário, voltando a ser pluripotentes.
} 
et. al, 2012, p.2216, tradução livre).

Essa primeira "prova" da eficácia e rentabilidade das CeSaM consolidou, no laboratório, a importância do seu cultivo para o desenvolvimento de pesquisas com células mesenquimais. Essa frente de trabalho foi levada adiante por Regina Goldenberg e pela então mestranda, e segunda autora desse primeiro artigo publicado sobre as CeSaM, Karina Asensi.

\section{CeSaM: Isolamento, Cultivo e Expansão}

Com a proposta de "seguir o sangue menstrual e suas células", apresentamos agora uma descrição do processo de isolamento, cultivo e expansão das CeSaM tal como estabelecido e "performado" no LCCM (MOL, 2003), e conforme registrado durante a pesquisa etnográfica em questão, acompanhando os experimentos do laboratório que utilizam as células do sangue menstrual. ${ }^{11}$ A quantidade de material inicial a ser coletada é muito pequena. As amostras geralmente chegam em potes coletores como os usados em exames clínicos de urina e fezes (Figura 1). Bastam um ou dois mililitros de sangue menstrual para iniciar o experimento.

\section{Figura 1 - Amostra de sangue menstrual}

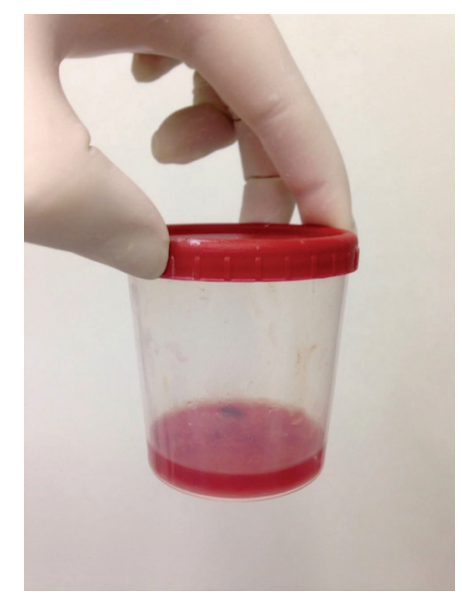

\footnotetext{
${ }^{11}$ As pesquisas desempenhadas no laboratório foram aprovadas pelo comitê de ética e pesquisa do Hospital Universitário Clementino Fraga Filho / UFRJ sob o processo de no 056/09.
} 
As doadoras, na maioria das vezes as próprias pesquisadoras do laboratório, recebem o pote com solução salina e antibióticos para evitar a proliferação de bactérias. Para doar o material, de acordo com o código de ética, elas devem assinar um termo de consentimento. A coleta é feita diretamente no pote coletor, no dia de maior fluxo menstrual.

O protocolo para "isolamento das células" dos demais componentes presentes no sangue menstrual envolve a sua mistura com outras substâncias e uma sucessão de centrifugações, que permitem que os diferentes componentes sejam separados. O isolamento pode ser feito de duas formas. Uma delas é usando um reagente químico que permite a separação celular por densidade. O objetivo principal é isolar, do sangue, as células mesenquimais das demais células e substâncias ali presentes (como as hemácias, granulócitos ${ }^{12} \mathrm{e}$ outros hemocomponentes).

Outra forma de realizar o isolamento das células é misturando uma solução salina tamponada com o sangue menstrual e colocando em dois tubos de plástico com quantidades iguais, e submetendo a mistura à centrifugação. Na primeira delas, já é possível ver (Figura 2) a parte acelular do sangue menstrual e a solução salina misturadas e, abaixo, um sedimento com as células presentes no sangue, como as hemácias, que têm a coloração vermelha, leucócitos, células epiteliais e células estromais mesenquimais.

Figura 2 - Processo de isolamento: sangue menstrual após centrifugação

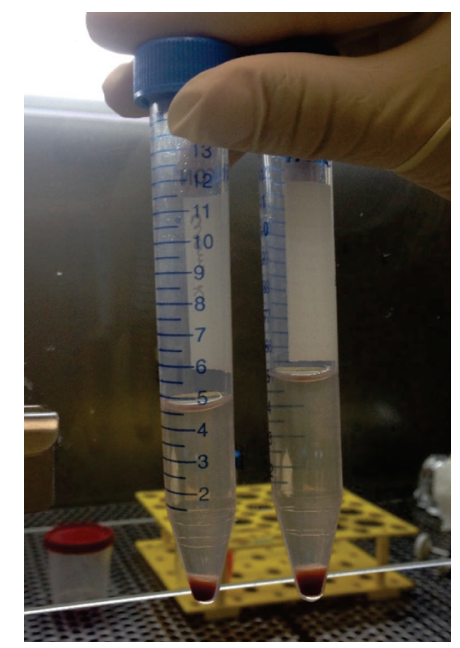

${ }^{12}$ Os granulócitos são células sanguíneas que apresentam muitos grânulos no seu interior. São elas: neutrófilos, basófilos e eosinófilos. 
A parte líquida acelular é descartada, e o material precipitado é diluído para ser, então, novamente "lavado" com solução salina e centrifugado. Após algumas repetições desses procedimentos, o material é misturado ao meio de cultura e procede-se ao "plaqueamento", que é o acondicionamento do líquido com as células numa placa de plástico. Esta é então nomeada com o tipo de célula (CeSaM), a data, o código da doadora e qual plaqueamento se trata (zero para o inicial, um para a próxima vez em que as células serão manipuladas e replaqueadas, e assim por diante).

Após dois dias do plaqueamento inicial, as células são "lavadas" com a solução salina e já há uma redução do "vermelho" do sangue para a tonalidade do meio de cultura (Figura 3). Com as lavagens, as células aderentes ao plástico da placa de cultura se tornam mais visíveis no microscópio. O procedimento todo objetiva uma purificação do elemento que interessa desse conjunto todo: as células estromais mesenquimais do sangue menstrual. Uma vez isoladas, as CeSaM se tornam uma "cultura" cuja manutenção depende de intensa atenção e cuidado por parte da pesquisadora, ${ }^{13}$ e a sequência de outros diversos tratamentos (colocação na estufa, replaqueamento, troca periódica do meio de cultura e congelamento).

Figura 3 - Plaqueamentos após zero (acima) e dois dias (abaixo)

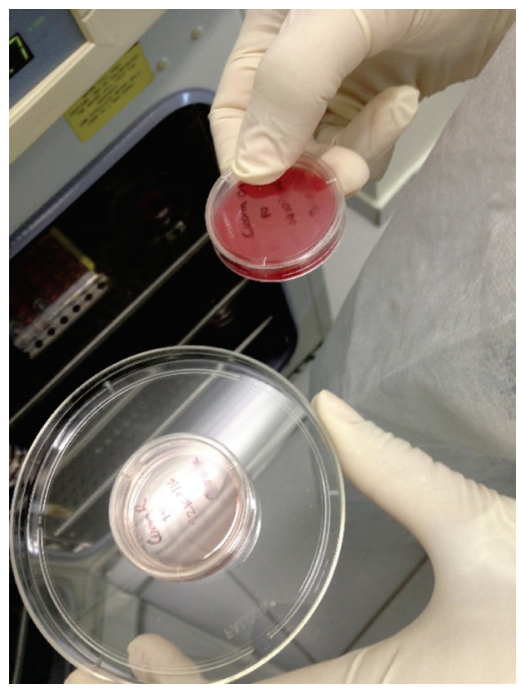

${ }^{13}$ O LCCM é majoritariamente formado por pesquisadoras mulheres. E desde a pesquisa de Deivid Rodrigues, nenhum outro pesquisador homem se envolveu diretamente com o cultivo dessas células. 
Não é, contudo, apagada definitivamente a origem de cada uma dessas células. No caso das CeSaM, ela é reiterada pela utilização dessa abreviatura que, assim como o processo de purificação/isolamento, atenua o peso da proveniência de um tecido marcado por gênero e sexualidade: sangue menstrual vira o sufixo "SaM" que sucede aquilo que de fato importa nesse contexto, o "Ce" das células.

Após algumas horas do isolamento, as células já começam a aderir no fundo da placa, a crescer e a multiplicar. Depois de alguns dias, elas tomam todo o fundo da placa com um aspecto confluente, que é a "morfologia fibroblastoide" desejada (Figura 4). ${ }^{14}$ Uma vez cheia a placa, o espaço para o crescimento das células é aumentado (elas são descoladas, centrifugadas e colocadas, junto com o meio em mais placas - e/ou em placas maiores). Isso é a expansão. Adicionalmente, após sua multiplicação, as células podem ser congeladas para posterior utilização.

Figura 4 - Fotomicrografias das CeSaM após 7 dias de cultivo

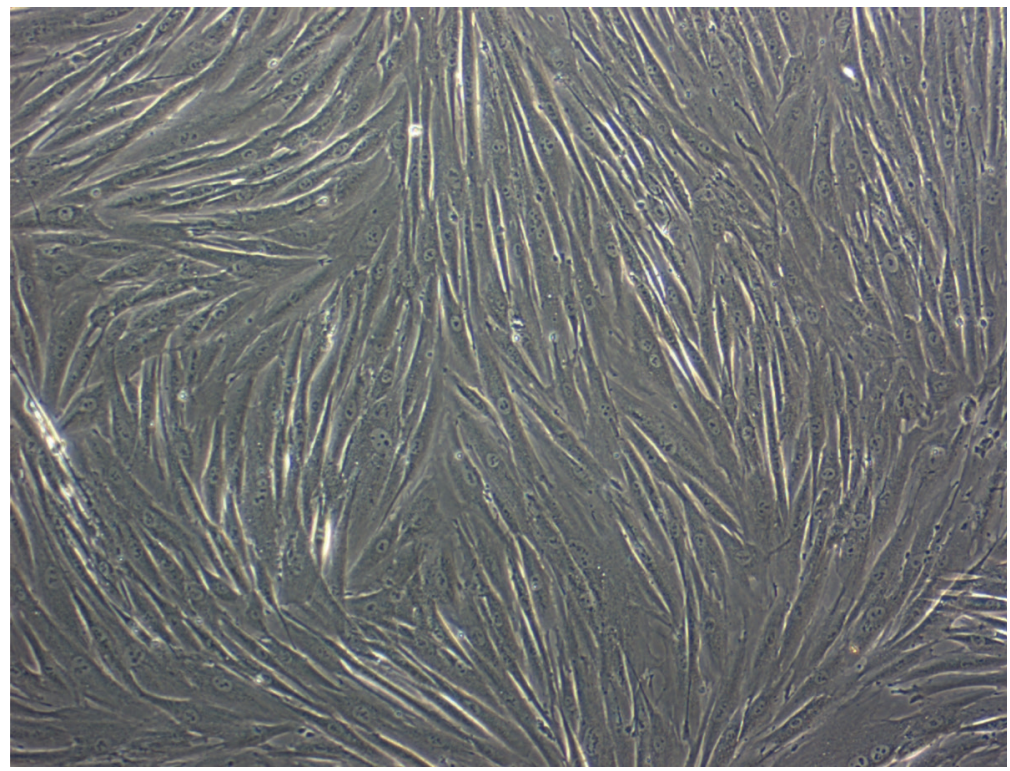

${ }^{14}$ A morfologia fibroblastoide é alongada e delgada, semelhante à dos fibroblastos. Os fibroblastos são células presentes no tecido conjuntivo, capazes de sintetizar e liberar diversas substâncias. 
A potência das CeSaM está ligada à sua capacidade de "aderir ao suporte de cultura, exibir uma morfologia fibroblastoide, além de apresentar uma alta taxa de proliferação dobrando a sua população em 19-36 horas (...), sugerindo que a expansão em larga escala é possível em uma proposta terapêutica" (ASENSI; GOLDENBERG; PAREDES, 2012, P. 112).

Conforme Asensi demonstrou com suas pesquisas de mestrado (ASENSI et. al., 2014) e doutorado, as CeSAM expandem rapidamente e resistem bem a condições de privação (pouco nutrientes no meio de cultura, pouco oxigênio). Esse é um dos fatores que as tornam interessantes tanto para pesquisas quanto para tratamentos clínicos. Mesmo uma pequena quantidade de sangue menstrual inicial pode ser revertida em milhares de células. Além disso, elas podem substituir tecidos não humanos que têm sido utilizados para cultivar as células embrionárias, como os fibroblastos embrionários de camundongos, reduzindo a necessidade dessa relação transespecífica em nível celular em pesquisas e eventuais tratamentos (SILVA DOS SANTOS et al., 2014).

O perfil das CeSaM tem se mostrado equivalente ao das células da medula óssea, de acordo com marcadores específicos (proteínas presentes nas membranas das células; substâncias que induzem a produção de outras substâncias, ou induzem o crescimento de determinada célula; e a capacidade de modular a resposta imunológica, evitando sua rejeição pelo organismo onde foi inserida). ${ }^{15}$ Têm uma sobrevida maior que a observada em células de outros tecidos, demorando mais tempo para perder a sua capacidade proliferativa em cultura. Têm, ainda, uma capacidade superior de resistência a condições desfavoráveis, tais como privação de nutrientes e oxigênio.

\section{CeSaM, Gênero e Tecnociência}

No laboratório, as CeSaM são jocosamente referidas como "células do chico", expressão popularmente usada para falar sobre a menstruação. Diz-se que a mulher "está de chico" quando está menstruada. A menção explícita à menstruação, fonte das células, é evitada. Como o é em outras

\footnotetext{
${ }^{15}$ As expressões mais técnicas para falar dessas moléculas marcadoras são, respectivamente, proteínas de superfície, fatores de transcrição e de crescimento e propriedades imunomodulatórias.
} 
situações sociais comuns que envolvem expressões de abjeção, nojo ou vergonha perante o sangue menstrual (SANABRIA, 2016).

Com efeito, no laboratório, a presença desse substrato corporal é quase efêmera: da chegada à coleta, já envasado pelo pote coletor, o material vai imediatamente, ou o quanto antes possível, para o procedimento de isolamento e plaqueamento descrito anteriormente. Algumas pesquisadoras relataram expressões de nojo por parte de outras pessoas em relação à manipulação do sangue menstrual no fluxo laminar, ou até mesmo situações em que outros pesquisadores evitaram usar o mesmo espaço ao mesmo tempo, receosos de alguma eventual contaminação. Apesar do rápido processamento, o sangue menstrual permanece constantemente referenciado pelo nome da célula (CeSaM), e/ ou pelo seu apelido.

As formas mais usuais e valorizadas de inscrição dos resultados das pesquisas (os artigos científicos da área) reduzem ou minimizam essa dimensão mais cotidiana do laboratório, na qual eventualmente um desconforto com a presença do sangue menstrual pode se expressar. Nos artigos, a referência à origem da célula é apresentada descrevendo-se objetivamente sua utilização e processamento nos materiais e métodos, e os procedimentos bioéticos de obtenção do material. As percepções pessoais acerca da presença do sangue menstrual nas dinâmicas do laboratório, e fora dele, em contextos de divulgação das pesquisas, ficam invisíveis nesta linguagem objetiva e codificada dos artigos. Este artigo oferece uma oportunidade de recompor e narrar, numa feitura coletiva e multidisciplinar, e partindo da pesquisa etnográfica realizada no laboratório, algumas dessas situações.

Comparativamente com os demais substratos corporais utilizados (medula, cordão umbilical, gordura etc.), o sangue menstrual é aquele que tem a maior disponibilidade potencial e ausência de invasividade para ser obtido - basta coletá-lo durante o fluxo menstrual, e em pequenas quantidades. As pesquisas realizadas até o presente momento demonstraram que o sangue menstrual é um excelente vetor de acesso para células humanas adultas, que podem ser cultivadas em laboratório, com plasticidade e capacidade de diferenciação vantajosas para a pesquisa científica e, possivelmente, para a terapia celular.

Contudo, é um substrato marcado por gênero e sexualidade de partida. Não só vem do tecido interno do útero, como passa pela vagina no seu caminho para "fora" do corpo. Essa passagem não é banal (SANABRIA, 2016), nem neutra, e isso se reflete no universo de pesquisas possíveis com 
células mesenquimais no LCCM. Não é à toa que a iniciativa do uso dessas células tenha sido tomada por uma pesquisadora mulher. E que sejam ainda poucas, e fundamentalmente mulheres, as pesquisadoras que participam das investidas com esse substrato corporal no laboratório.

Apesar da primeira publicação importante sobre as CeSaM, neste laboratório, ter sido parte da pesquisa de um pesquisador, e a célula ter demonstrado a sua excelência e utilidade, rapidamente outros substratos corporais (como o sangue de cordão umbilical e a gordura) passaram a ser estudados para desenvolver o mesmo tipo de ação. Embora estes tenham, proporcionalmente, uma quantidade inferior de células, demandando uma amostragem inicial maior, ou mais tempo de cultivo e expansão, parece haver uma preferência maior (ainda consensual na comunidade científica da área, e também no LCCM) de evitar o uso do sangue menstrual, sempre que for possível.

Diferentemente das demais células de tecido adulto pesquisadas (como as da placenta, do cordão umbilical etc.), as CeSaM são muitas vezes pensadas como sendo células exclusivas "das mulheres" - que seriam empregáveis apenas em mulheres nos eventuais tratamentos futuros. Não há, entretanto, do ponto de vista científico, nenhum impedimento adicional ao trânsito das células do sangue menstrual para corpos masculinos, comparativamente a outros tecidos utilizáveis, desde que sejam compatíveis. A não ser, é claro, em casos de tratamentos autólogos. A marcação de gênero opera de maneira a impossibilitar que a CeSaM seja tratada como uma célulamodelo, que pudesse ser universalmente estudada para tratamentos em corpos humanos.

As pesquisadoras que "compraram a ideia" de trabalhar com as CeSaM e que têm bancado tudo o que envolve esse empreendimento (convidar mulheres a doar material, "dar o próprio sangue" menstrual para a pesquisa, apresentar o trabalho em congressos científicos, falar sobre a pesquisa com outras pessoas, defender e divulgar seus resultados) precisam também encarar os eventuais (mas inevitáveis) comentários jocosos, piadas machistas, apelidos engraçados sobre a fonte da célula. Cenas de bastidores, que muitas vezes passam desapercebidas, sobrepõem, de certa forma, uma misoginia (implícita, e às vezes mais explícita) na sociedade, às próprias células.

Em uma das situações presenciadas durante a pesquisa de campo, ao comentar resultados de um experimento com as CeSaM, que não apontavam uma diferença significativa a ponto de ser valorizada e publicável, uma das 
pesquisadoras ouviu de um pesquisador que estava avaliando seu trabalho que, se os resultados (e procedimentos de pesquisa) não fossem diferentes, a única coisa que ela provaria é que as CeSaM "só servem mesmo é para acabar num "modess"16".

Essa cena expressa a exigência que se costuma fazer ao desempenho das CeSaM: é preciso que se juntem resultados suficientemente convincentes sobre ela, de acordo com os mais rigorosos parâmetros científicos vigentes, como o é para qualquer outra célula, para que ela seja reconhecida como boa. Entretanto, nenhuma das outras células será (ou foi) acusada da sua inutilidade ou ineficiência em termos tão pejorativos, marcados por comentários de cunho machista, ou que invoquem de maneira tão explícita a expectativa socialmente compartilhada em relação ao sangue menstrual: que ele não serve para nada, é inútil, deve ser descartado como lixo e sempre ocultado e escondido, de acordo com as regras de higiene sanitária.

Nem mesmo as células do tecido adiposo, oriundas dos excedentes de clínicas de lipoaspiração (e que vêm sendo também bastante estudadas, parte em razão da ampla e crescente disponibilidade de material) parecem receber o mesmo tratamento. Em geral se brinca com o benefício de se "livrar" do excesso de gordura no corpo, reiterando pressupostos de saúde e beleza (que também incidem sobre gênero). Mas, apesar de compartilharem a jocosidade na forma como é retratado seu uso em pesquisas, as CeSaM e as células da gordura não dividem o estigma da marcação por gênero, sendo o uso dessas últimas em pesquisas e terapias visto com muito mais neutralidade, entusiasmo e esperança. ${ }^{17}$

Não há como não pensar esse tipo de abordagem sobre a função e desempenho das CeSaM sem estabelecer uma analogia com a forma como minorias (como "mulheres", por exemplo) são também cobradas a respeito de seu desempenho. Ou seja, a expectativa da performance das CeSaM em laboratório espelha, ou sobrepõe, de certa maneira, aquilo que se espera de minorias, na ciência e no mundo do trabalho assalariado de forma geral: que, em situações de comparação ou competição, provem

\footnotetext{
${ }^{16}$ Modess é uma marca antiga de absorventes higiênicos usada para conter e descartar o sangue menstrual.

${ }^{17}$ Ver, por exemplo, o uso terapêutico que vem sendo feito em clínicas veterinárias usando células do tecido adiposo do próprio animal para tratar algumas disfunções. Disponível em: http://www.cellvet.com.br/terapia-celular/. Acesso em junho de 2017.
} 
sua excepcionalidade (ou seu desempenho muito acima da média), sua alta capacidade de "dar conta do recado", ou então que se recolham a um lugar minoritário e se conformem com a grande probabilidade de serem preteridas por uma pessoa menos "marcada" (por gênero, raça, classe ou qualquer outra condição minoritária) e tão eficaz quanto.

Essa analogia que estabelecemos aqui brinca com os estereótipos de gênero no mundo (da ciência, inclusive) e apenas reforça uma questão já bastante consolidada nos estudos de gênero e ciência. Mas é, ao mesmo tempo, infelizmente, bastante verossímil em relação ao contexto de pesquisa em questão. Apesar de produzirem resultados excelentes, as CeSaM ainda ocupam, no universo de pesquisas do LCCM, uma posição secundária ou marginal em relação a outras fontes de células.

Sua perspectiva de um engajamento central em pesquisas maiores, de fôlego, projetos grandes e coletivos que concorram nos maiores editais é praticamente nula, ou bastante improvável. Pelo contrário, nesse tipo de projeto ela sequer costuma ser incluída entre as células a serem utilizadas. Maior visibilidade é dada a substratos corporais menos marcados, ainda que o uso destes envolvam procedimentos mais invasivos (ou menos disponíveis) para obtenção. São privilegiadas a medula óssea (que já tem um lugar tradicional e consolidado nesse universo de pesquisas), o tecido adiposo, os excedentes do parto e gestação (líquido amniótico, cordão, placenta), e até mesmo a polpa do dente de leite.

Curiosamente, ao que tudo indica, a CeSaM resiste, como uma espécie de ícone do que se espera ser uma ciência e uma prática feminista, ou afetada por um feminismo, que não se furta de valorizar o corpo entendido como feminino, em sua possível especificidade: ela responde bem a situações desafiadoras, como falta de nutrientes e pouco oxigênio, perdura, resiste, quando tensionada pelos experimentos em questão. Isso tem a ver com o fato de essas células serem extraídas de corpos jovens e sadios, como costuma ser o perfil das doadoras de sangue menstrual, ao contrário de outras fontes, como o líquido amniótico, extraído em situações que envolvem o exame de amniocentese, ou mesmo os embriões de clínicas de reprodução assistida, que são considerados "inviáveis". São células mais "felizes" por isso. Mas pode ter a ver também com o fato de serem células de um tecido que é "desafiado", "estressado", "impactado" muito mais frequentemente que os demais tecidos disponíveis para pesquisa. É um pressuposto implícito das pesquisas em questão que a descamação periódica do tecido endometrial com a menstruação talvez tenha favorecido o desenvolvimento de células- 
tronco com uma alta capacidade de resistência a situações adversas.

Os resultados das pesquisas até o momento permitem caracterizar as CeSaM como células fortes, resistentes. Portanto, por virem de órgãos mais impactados e de corpos que têm mais vitalidade, essas células "vivem" muito bem nos laboratórios, "trabalham" bem nas pesquisas para as quais são convocadas, que envolvem, inclusive, colocá-las na posição de restauro e reparação, de cura e de cuidado. As CeSaM, para além de compor uma excelente metáfora sobre o trabalho, o corpo e a vida de mulheres, performam, também, efetivamente, em laboratório, um mundo potencial no qual quiçá o sangue menstrual poderá sair da sua condição de excremento abjeto para a nobre função de vir a salvar vidas. Isso se conseguir ultrapassar o machismo institucional. ${ }^{18}$ De qualquer maneira, (e que não se cobre demais dele!) já tem servido muito bem, muito melhor do que muitos outros tecidos corporais, para a produção de conhecimento científico acerca da potência vital e terapêutica das células mesenquimais.

\section{Referências}

ALMEIDA, João Aprígio.

(1999). Amamentação: um híbrido naturezacultura. Rio de Janeiro, Editora FIOCRUZ.

ALZUGUIR. Fernanda; NUCCI, Marina.

(2015). Maternidade mamífera? Concepções sobre natureza e ciência em uma rede social de mães. Mediações. Vol. 20, n. 1, p. 217-238.

ASENSI, Karina Dutra; GOLDENBERG, Regina C. S.; PAREDES, Bruno.

(2012). 0 sangue menstrual como fonte de células-tronco mesenquimais. In: GOLDENBERG, Regina Coeli dos Santos Goldenberg; Antonio Carlos Campo de
Carvalho (0rg.); Células-tronco Mesenquimais: conceitos, métodos de obtenção e aplicações. Rio de Janeiro, Atheneu. p. 107-123.

ASENSI, Karina Dutra; FORTUNATO, Rodrigo S.; SILVA dos SANTOS, Danúbia; Pacheco, Thaísa S.; REZENDE, Danielle F. de; RODRIGUES, Deivid C.; MESQUITA, Fernanda C. P.; KASAI-BRUNSWICK, Taís H.; CAMPOS DE CARVALH0, Antonio C.; CARVALH0, Denise P.; CARVALH0, Adriana B.; GOLDENBERG, Regina C. S.

(2014). Reprogramming to a pluripotent state modifies mesenchymal stem cell resistance to oxidative stress. Journal of Cellular and Molecular Medicine, v. 18, n.5, p. 824-831.

\footnotetext{
${ }^{18}$ Caberia, evidentemente, problematizar diversas questões a respeito desse potencial de uso das CeSaM: o consentimento das doadoras, a universalidade e gratuidade no acesso às células e terapias, as políticas de propriedade intelectual e do mercado biomédico e farmacêutico que incidem sobre terapêuticas possíveis etc. Não queremos naturalizar a positividade do uso das CeSaM, mas indicar o quanto esse potencial é sistematicamente impedido pela institucionalidade vigente que (ainda) enxerga o corpo feminino como diferente e, o que é mais problemático, como inferior.
} 
BERTHON-MOINE, Ingrid.

(2011). Red is the colour. Women's Studies: an inter-disciplinary journal. v. 40, n. 2, p. 247248.

BOBEL, Chris; KISSLING, Elizabeth.

(2011). Menstruation Matters: introduction to representations of the menstrual cycle. Women's Studies: an inter-disciplinary journal. v. 40, n. 2, p. 121-126.

BOBEL, Chris.

(2010). New blood: third-wave feminism and the politics of menstruation. New Brunswick / New Jersey / London, Rutgers University Press.

BUTLER, Judith.

(1993). Bodies that matter: on the discursive limits of sex. New York, Routledge.

CARNEIRO, Rosamaria G.

(2014). De perto e de longe do que seria natural, mais natural e/ou humanizado: uma etnografia dos grupos de preparo para o parto humanizado. In: Soraya Fleischer; Jaqueline Ferreira (Orgs.); Etnografias em Serviços de Saúde. 1ed. Rio de Janeiro, Garamond. p. 243-266.

(2012). 0 que querem as "mulheres que comem placenta"? Práticas de parto sexualizadas e subjetivantes. In: Luiz Mello; Dalva Borges Souza; Jordão Horta Nunes; Flávio Munhoz Sofiati (Orgs.); Questões de Sociologia. Debates contemporâneos. 1ed. Goiânia, Cânone Editorial. p. 171-190.

CARSTEN, Janet.

(2013). Introduction: blood will out. Journal of the Royal Anthropological Institute (N.S.), S1-S23.

CARVALH0, Antonio Carlos C.; GOLDENBERG, Regina C.; BRUNSWICK, Tais.

(2012). Células-tronco: conceito, utilização e centros avançados de obtenção. In: CARVALHO, A.C.C e GOLDENBERG, R.C.S. Células-tronco mesenquimais: conceitos, métodos de obtenção e aplicações. São Paulo: Editora Atheneu. p. 2-8.
CESARIN0, Letícia da Nóbrega.

(2007). Nas fronteiras do "humano": os debates britânico e brasileiro sobre a pesquisa com embriões. Mana, v. 13, n. 2, p. 347-380.

COUTINHO, Elsimar.

(1996). Menstruação: a sangria inútil. São Paulo, Editora Gente.

CUI, Chang-Hao; UYAMA, Taro; MIYAD0, Kenji; TERAI, Masanori; KYO, Satoru; KIYONO, Tohru, UMEZAWA, Akihiro.

(2007). Menstrual blood-derived cells confer human dystrophin expression in the murine model of Duchenne muscular dystrophy via cell fusion and myogenic transdifferentiation. Molecular Biology of the Cell, v.18, p.15861594.

DINIZ, Carmen Simone.

(2005). Humanização da assistência ao parto no Brasil: os muitos sentidos de um movimento. Ciência e Saúde Coletiva, v. 10, n.3, p. 627-637.

FINE, Agnès.

(2003). Leite envenenado, sangue perturbado. Saber médico e sabedoria popular sobre os humores femininos (século XIX e XX). IN: MATOS, Maria Izilda; SOIHET, Rachel. 0 corpo feminino em debate. São Paulo, Editora UNESP. p. 57-78.

FLEISCHER, Soraya.

(2011). Parteiras, buchudas e aperreios. Uma etnografia do atendimento obstétrico não oficial em Melgaço, Pará. Belém / Paka-Tatu / Santa Cruz do Sul, EDUNISC.

(2007). Sangue, Leite e Quarentena: Notas etnográficas sobre o puerpério na cidade de Melgaço, Pará. Campos: Revista de Antropologia Social, v. 8, n. 2, p. 81-97.

HARAWAY, Donna.

(1990). Simians, cyborgs and women: the reinvention of nature. New York, Routledge.

LATOUR, Bruno; STARK, Monique G.

(1999). Factures / Fractures: From the Concept of Network to the Concept of Attachment. RES: Anthropology and Aesthetics, n. 36. p. 20-31. 
LUNA, Naara.

(2007). A representação do corpo como recurso: pesquisa com células-tronco em uma instituição de ensino. Revista de Antropologia, v. 50, n. 2 , p. 683-712.

MANICA, Daniela; NUCCI, Marina.

(2017). Sob a pele: implantes subcutâneos, hormônios e gênero. Horizontes Antropológicos. v. 23, n. 47. p. 93-129.

MANICA, Daniela; RIOS, Clarice.

(2017). (In)visible blood: menstrual performances and body art. Vibrant, v. 14, n.1, p. 124-148.

MARTIN, Emily.

(2006). A mulher no corpo. Rio de Janeiro, Ed. Garamond.

MEDEIROS, Flávia N.

(2012). As múltiplas representações de Dolly nos discursos sobre a clonagem. Intercom $R B C C$, v. 35, n. 1, p. 93-110.

MOL, Annemarie.

(2003). The body multiple: Ontology in medical practice. Durham, Duke University Press.

NOBRE, Júlio Cesar de Almeida; PEDR0, Rosa Maria Leite Ribeiro.

(2014). Vida humana, mídia e mercado: uma perspectiva sociotécnica das pesquisas com células tronco embrionárias. Estudos e Pesquisas em Psicologia. Rio de Janeiro v. 14 n. 1, p. 320-336.

PEREIRA, Lygia da Veiga.

(2008). A importância do uso das células tronco para a saúde pública. Ciência \& saúde coletiva. v. 13, n.1, p. 7-14.

RODRIGUES, Deivid de Carvalho; ASENSI, Karina Dutra; VAIRO, Leandro; AZEVEDO-PEREIRA, Ricardo Luiz; SILVA, Rosane; RONDINELLI, Edson; GOLDENBERG, Regina Coeli; CAMPOS DE CARVALHO, Antonio Carlos; ÜRMÉNYI, Turán Péter.

(2012). Human Menstrual Blood-Derived Mesenchymal Cells as a Cell Source of Rapid and Efficient Nuclear Reprogramming. Cell Transplantation, v. 21, p. 2215-2224.
SANABRIA, Emilia.

(2016). Plastic bodies: sex hormones and menstrual suppression in Brazil. Durham / London, Duke University Press.

SILVA DOS SANTOS, Danúbia; OLIVEIRA, Vanessa Carvalho Coelho; ASENSI, Karina Dutra; VAIRO, Leandro; CARVALH0, Adriana Bastos; CARVALH0, Antonio Carlos Campos; GOLDENBERG, Regina Coeli dos Santos.

(2014). Human Menstrual Blood-Derived Mesenchymal Cells as New Human Feeder Layer System for Human Embryonic Stem Cell. Cell Medicine, v. 7, p. 25-35.

TAKAHASHI , Kazutoshi; YAMANAKA, Shinya.

(2006). Induction of Pluripotent Stem Cells from Mouse Embryonic and Adult Fibroblast Cultures by Defined Factors. Cell, v. 126, n. 4, p. 663-676.

TORNQUIST, Carmen Susana.

(2002). Armadilhas da nova era: natureza e maternidade no ideário da humanização do parto. Revista Estudos Feministas, v. 10, n. 2.

WALDBY, Catherine; MITCHELL, Robert.

(2006). Tissue economies: blood, organs and cell lines in late capitalism. Durham / London, Duke University Press.

WILSON, Elisabeth.

(2015). Gut Feminism. Durham / London, Duke University Press.

\section{Recebido em}

outubro de 2017

\section{Aprovado em}

março de 2018 